\title{
Togaviridae Infection
}

National Cancer Institute

\section{Source}

National Cancer Institute. Togaviridae Infection. NCI Thesaurus. Code C85192.

A viral infection caused by any of the arboviruses of the Togaviridae family. It is transmitted by arthropods. Signs and symptoms include fever, headache, nausea, vomiting, rash, confusion, and seizures. 